\title{
SINTESIS SILIKA MCM-41 DAN UJI KAPASITAS ADSORPSI TERHADAP METILEN BIRU
}

\section{SYNTHESIS OF SILICA MCM-4 AND ITS ADSOPTION CAPACITY FOR METHYLENE BLUE}

\author{
Mustofa Ahda, Sutarno*, Eko Sri Kunarti* \\ Fakultas Farmasi Universitas Ahmad Dahlan \\ Jln. Prof. Dr. Supomo Yogyakarta, Telp. (0274) 379418 \\ Email :mustofa_ahda@yahoo.com
}

\begin{abstract}
Abstrak
Telah disintesis MCM-41 dengan variasi waktu hidrotermal 18, 24, 36, 48 jam menggunakan agen pengarah struktur cetiltrimetilammonium bromida (CTAB). Hasil penelitian menunjukkan bahwa waktu hidrotermal mempengaruhi intensitas dan indeks bidang $\left(a_{o}\right)$. Sintesis MCM-41 dengan waktu hidrotermal 24 jam menghasilkan intensitas tertinggi yang menunjukkan bahwa MCM-41 memiliki kristalinitas terbaik. sedangkan uji kapasitas MCM-41 tersebut memiliki kemampuan adsorpsi terhadap metilen biru sebesar 37,037 mg/g.
\end{abstract}

Kata kunci : MCM-41, Kapasitas Adsorpsi, Metilen Biru

*)Fakultas MIPA KIMIA Universitas Gadjah Mada 


\section{Abstract}

Synthesis of MCM-41 with hydrothermal time variation 18, 24, 36, 48 hours using templating agent cetiltrimetilammonium bromide (CTAB) has been done. The results showed that the time of hydrothermal influence the intensity and the index field $\left(a_{0}\right)$. Synthesis of MCM-41 with a time of hydrothermal 24 hours produce the highest intensity which indicates that MCM-41 has the best crystallinity. While testing the adsorption capacity of MCM-41 has $37,037 \mathrm{mg} / \mathrm{g}$ for adsorption of the methylene blue.

Key words : MCM-41, Adsorption Capacity, Methylene Blue

\section{PENDAHULUAN}

Pengembangan dan pemanfaatan nanoteknologi pada akhir-akhir ini berkembang pesat. Perkembangan nanoteknologi meliputi pada model, sintesis, karakterisasi dan aplikasi material serta alat pada skala nano. Pengembangan nanoteknologi yang mengarah pada masalah kedokteran atau kesehatan yang dinamakan sebagai "nanomedicine". Salah satu pemanfaatan dan pengembangan nanoteknologi dalam bidang farmasi ialah memanfaatkan nanomaterial sebagai "solid support" suatu obat.

Salah satu material yang dapat digunakan ialah Mobil Composition of Matter No. 41 (MCM-41). Hal ini karena MCM-41 merupakan material yang memiliki susunan pori heksagonal yang teratur dan susunan matriks silikanya seperti sarang lebah (Kim, dkk., 1995). Ukuran pori heksagonal pada MCM-41 ini menjadikan material tersebut dapat melakukan proses adsorpsi terhadap suatu obat. Proses teradsorpsinya obat dalam pori-pori MCM-41 ini menjadikan dasar bahwa MCM-41 dapat digunakan sebagai solid support. Terjadinya proses adsorpsi obat dalam pori MCM-41 sering juga dikenal dengan enkapsulasi obat. Proses enkapsulasi obat pada nanomaterial MCM-41 sehingga dapat digunakan dalam dunia kesehatan. Menurut Regi (2012) menyatakan bahwa material silica mesopori sangat potensial dalam nanomedicine. Pemanfataan MCM-41 dalam dunia kedokteran dikarenakan nanopartikel MCM-41 memiliki sitotoksik yang rendah (Patil, dkk., 2011)

Penelitian ini memfokuskan pada proses sintesis MCM-41 dan uji kemampuan adsorpsinya. Pembentukan MCM-41 menggunakan surfaktan cetil trimetil ammonium bromida (CTAB) sebagai pengarah struktur kerangka MCM-41. MCM-41 disintesis dengan variasi waktu hidrotermal. Xu dkk. (1998) dan Mokaya (2001) menyatakan bahwa morfologi MCM-41 sangat dipengaruhi oleh waktu hidrotermal. Sedangkan proses uji kemampuan adsorpsi MCM-41 sebagai landasan aplikasi lebih lanjut dalam proses enkapsulasi obat. Penentuan kemampuan adsorpsi MCM-41 dengan menentukan kapasitas adsorpsinya. 
Penelitian kali ini untuk menguji kapasitas adsorpsi MCM-41 menggunakan obyek metilen biru karena memiliki molekul yang relatif besar. sehingga nantinya dapat menjadikan gambaran umum untuk proses enkapsulasi terhadap obat yang memiliki struktur besar.

\section{METODE PENELITIAN}

\section{Bahan}

Bahan-bahan yang digunakan dalam penelitian ini meliputi: natrium silikat $\quad \mathrm{Na}_{2} \mathrm{SiO}_{3} .9 \mathrm{H}_{2} \mathrm{O} \quad(27 \% \quad \mathrm{SiO} 2$, Merck), cetil trimetil ammmonium bromida (CTAB, Merck), $\mathrm{CH}_{3} \mathrm{COOH}$ (Merck), akuades, dan metilen biru (CI. 52015, Merck).

\section{Alat}

Alat-alat yang digunakan dalam penelitian ini adalah beaker plastik, kaca arloji, erlenmeyer, penyaring Buchner, pipet tetes, labu ukur, pipet ukur dan termometer, sertadidukung oleh peralatan seperti neraca analitik (Mettler AE 160), pengaduk magnetik, furnace (Fischer Scientific $655 \mathrm{~K}$ ), desikator, autoklaf, tabung sentrifugasi, sentrifugasi, difraktometer sinar-X (Simadzu XRD 6000), surface area analyzer (Quantachrome NovaWin2 version 2.2), spektrofotometer UV-visibel (Hittachi U-2010).

\section{Jalannya Penelitian}

\section{Sintesis silika MCM-41}

MCM-41 disintesis dengan komposisi molar campuran $1 \mathrm{SiO}_{2}: 0,25$
CTAB : O,29 $\mathrm{Na}_{2} \mathrm{O}: 50 \mathrm{H}_{2} \mathrm{O}$. Sebanyak 2,277 g CTAB dilarutkan dalam 18,882 $\mathrm{g}$ aquades selama 30 menit pada temperatur $60^{\circ} \mathrm{C}$ dan didinginkan. Setelah itu ditambahkan 7,512 g larutan $\mathrm{Na}_{2} \mathrm{SiO}_{3}$ tetes demi tetes dan dilakukan pemanasan pada temperatur $60^{\circ} \mathrm{C}$ selama 1 jam dengan diaduk sampai homogen dan didinginkan kembali. Kemudian $\mathrm{pH}$ campuran diatur pada $\mathrm{pH} 10$ dengan menambahkan asam asetat $1 \mathrm{M}$ dan dilakukan pengadukan selama 2 jam. Campuran dimasukkan dalam autoklaf dan dipanaskan pada temperatur $100^{\circ} \mathrm{C}$, dengan variasi waktu hidrotermalnya selama 12, 24, 48 dan 88 jam.pH akhir campuran menunjukkan kenaikan sampai $\mathrm{pH}$ 11. Campuran disaring dan dicuci dengan akuades sampai netral kemudian dikeringkan dalam oven pada temperatur $100^{\circ} \mathrm{C}$ semalam. Kemudian MCM-41 dikalsinasi pada temperatur $550^{\circ} \mathrm{C}$ selama $5 \mathrm{jam}$. Hasil sintesis dikarakterisasi dengan difraksi sinar-X, spektrometer inframerah dan surface area analyzer.

\section{Uji Kapasitas Adsorpsi MCM-41}

Sebanyak 0,0205 g material MCM-41 dimasukkan ke dalam erlenmeyer yang berisi $20 \mathrm{~mL}$ larutan metilen biru dengan variasi konsentrasi antara 10-90 ppm untuk MCM-41. Proses adsorpsi ini dilakukan tanpa adanya pengaturan $\mathrm{pH}$ adsorbat. Campuran kemudian diaduk selama 120 menit. Kemudian padatan adsorben dipisahkan dari larutan dengan disentrifugasi pada $7000 \mathrm{rpm}$ selama 10 menit. Setelah dipisahkan kemudian larutan metilen biru dianalisis dengan menggunakan spektrometer UV-visibel 
(Hitachi, U2010) pada panjang gelombang $664 \mathrm{~nm}$.

\section{HASIL DAN PEMBAHASAN}

\section{A. Sintesis MCM-41}

Proses sintesis material mesopori MCM-41 sangat dipengaruhi oleh beberapa faktor seperti rasio silika/ surfaktan, $\mathrm{pH}$, temperatur dan jumlah pelarut. MCM-41 disintesis dalam kondisi basa dengan komposisi molar $\mathrm{SiO}_{2}$ : 0,25 CTMABr : O,25 $\mathrm{Na}_{2} \mathrm{O}: 50$ $\mathrm{H}_{2} \mathrm{O}$ dengan $\mathrm{pH}$ sekitar 10. Pengaturan $\mathrm{pH}$ dilakukan karena $\mathrm{pH}$ mempengaruhi anion silika dalam membentuk MCM-41. Sekitar $\mathrm{pH}=10$, pada konsentrasi surfaktan tinggi maka spesies anion silika dalam bentuk oligomernya $\quad\left[\mathrm{Si}_{4} \mathrm{O}_{8}(\mathrm{OH})_{4}\right]^{4-}$ dan $\left[\mathrm{Si}_{4} \mathrm{O}_{8}(\mathrm{OH})_{6}\right]^{2-}$ bukan dalam bentuk monomernya yaitu $\left[\mathrm{SiO}(\mathrm{OH})_{3}\right]^{-}$dan $\left[\mathrm{SiO}_{2}(\mathrm{OH})_{2}\right]^{2-}$. Oleh karena itu pengaturan $\mathrm{pH}$ sangat mempengaruhi hasil sintesis MCM-41. Hal ini sesuai penelitian Ryoo dan Kim (1995) yang menjelaskan bahwa pembentukan MCM-41 sangat sensitif terhadap $\mathrm{pH}$ dan hasil MCM-41 terkalsinasi dengan pengaturan $\mathrm{pH}$ memiliki pola difraksi sinar-X lebih baik dibandingkan MCM-41 tanpa pengaturan $\mathrm{pH}$. Selain itu, Ryoo dan Jun (1997) telah melakukan pengujian hidrotermal pada MCM-41, dan hasil menunjukkan bahwa stabilitas hidrotermal material dengan pengaturan $\mathrm{pH}=10,2$ lebih baik dibandingkan dengan tanpa pengaturan $\mathrm{pH}$.

Pengaturan $\mathrm{pH}$ dalam penelitian ini dilakukan dengan menggunakan asam asetat $1 \mathrm{M}$. Asam asetat digunakan sebagai pangatur $\mathrm{pH}$ sintesis ini dikarenakan asam asetat memiliki keunggulan sehingga MCM-41 yang dihasilkan memiliki stabilitas termal yang lebih baik. Hal ini didasarkan penelitian yang dilakukan oleh Mody dkk. (2008) bahwa hasil kristalinitas MCM-41 setelah kalsinasi pada $848 \mathrm{~K}$ dengan menggunakan asam sulfat lebih tinggi daripada menggunakan asam asetat, akan tetapi penggunaan asam asetat mampu menghasilkan stabilitas termal dan keteraturan yang lebih baik dibandingkan menggunakan asam sulfat.

Selain $\mathrm{pH}$, temperatur juga menjadi hal yang penting dalam mempengaruhi sintesis MCM-41. Hal ini dikarenakan MCM-41 dalam proses kristalisasi sangat tergantung pada temperatur. Pengaruh temperatur terhadap sintesis material mesopori MCM-41 dapat berupa kenaikan temperaturnya atau lama waktu kontak pemanasan selama proses sintesis. Penelitian yang dilakukan Corma dkk. (1997) menyimpulkan bahwa peningkatan temperatur kristalisasi dapat meningkatkan laju perbesaran (Swelling Rate), dimana pada temperatur kristalisasi $175^{\circ} \mathrm{C}$ selama 14 jam menghasilkan MCM-41 dengan unit sel $\left(\mathrm{a}_{\mathrm{o}}\right)$ sebesar $70 \AA$ yang lebih besar dari pada yang diperoleh dengan temperatur kristalisasi $135^{\circ} \mathrm{C}$ selama 50 hari yang menghasilkan unit sel $\left(a_{0}\right)$ sebesar 64,4 A..

Hasil sintesis MCM-41 pada penelitian ini memiliki kristalinitas yang tinggi dan tingkat keteraturan yang baik. Kristalinitas MCM-41 ditandai dengan munculnya puncak utama pada bidang [100] didaerah $2 \mathrm{O}$ sekitar $24^{\circ} \mathrm{C}$ dengan intensitas yang tinggi dan keteraturan 
struktur heksagonal dari kristalin MCM-41 didukung dengan munculnya puncak-puncak lain sekitar $2 \mathrm{O}$ pada daerah $4-5^{\circ}$ yang menunjukkan indeks bidang [110] dan [200] (Gambar 1).

Hasil penelitian ini menunjukkan bahwa pengaruh lama waktu hidrotermal ternyata mampu menyebabkan hasil kristalinitas MCM-41 berubah. MCM-41 yang disintesis dengan waktu hidrotermal selama 18 jam dan 24 jam mengalami kenaikan intensitas dengan kenaikan waktu hidrotermal. Hal ini karena dengan bertambahnya waktu hidrotermal maka akan mengalami proses kristalisasi lebih lanjut sehingga membentuk material dengan kristalinitas yang lebih baik. Akan tetapi semakin lama waktu hidrotermal ( $>24$ jam) mampu menyebabkan terjadinya penurunan intensitas MCM-41 yang dihasilkan sehingga menyebabkan penurunan kritalinitasnya (Gambar 1).

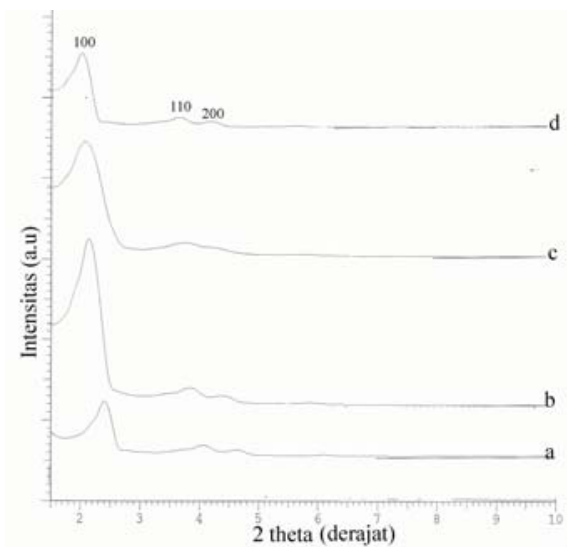

Gambar 1. Pola difraksi sinar-X pada MCM-41 yang disintesis dengan variasi waktu hidrotermal: a) 18 jam, b) 24 jam, c) 48 jam dan d) 88 jam
Besarnya penurunan MCM-41 yang disintesis dengan waktu hidrotermal 48 jam menghasilkan kristalinitas relatif lebih dari $50 \%$ dibandingkan dengan nilai intensitas tertinggi, akan tetapi dengan waktu hidrotermal 88 jam menghasilkan kristalinitas relatif menjadi dibawah 50\% (Tabel I). Fenomena ini dikarenakan adanya proses penataan struktur lebih lanjut bahkan dapat dimungkinkan dapat terjadinya transformasi lebih lanjut membentuk material lain seperti MCM-48 dan MCM-50. Hal ini sesusai dengan penelitian Mokaya (2001) yang menyatakan bahwa memperpanjang waktu kristalisasi pada sintesis MCM-41 secara hidrotermal, menyebabkan terjadinya tahapan transformasi dari partikel bentuk bola ke batang dan akhirnya ke bentuk tali dan proses transformasi ini merupakan induksi hidrotermal dan pengaruh dari waktu kristalisasi, disertai dengan pembentukan dinding pori silika yang sangat tebal dan kondensasi yang tinggi. $\mathrm{Xu}$ dkk. (1998) juga menyimpulkan bahwa proses transformasi melalui rangkaian fase heksagonal berubah ke fase satu lamelar kemudian berubah ke fase kubus kemudian berubah ke fase dua lamelar.

Hasil penelitian ini dapat disimpulkan bahwa waktu hidrotermal dalam sintesis MCM-41 juga mempengaruhi parameter unit sel $\left(\mathrm{a}_{\mathrm{o}}\right)$. Semakin lama waktu hidrotermal menyebabkan parameter unit sel $\left(\mathrm{a}_{\mathrm{o}}\right)$ yang dihasilkan pun meningkat. Variasi waktu hidrotermal dari 18 jam sampai 88 jam mampu menyebabkan terjadinya peningkatan parameter unit sel $\left(\mathrm{a}_{0}\right)$ sebesar 42,2 Å sampai 47,6 A. 
Jurnal Ilmiah Kefarmasian, Vol. 3, No. 1, $2013: 1$ - 8

Tabel I. Pengaruh waktu hidrotermal terhadap karakter MCM-41

\begin{tabular}{|c|c|c|c|c|}
\hline \multirow{2}{*}{$\begin{array}{c}\text { Waktu } \\
\text { Hidrotermal } \\
(\text { Jam) }\end{array}$} & Intensitas & $\mathbf{d}_{\mathbf{1 0 0}}$ & $\begin{array}{c}\text { Kristalinitas } \\
\text { Relatif } \\
(\%)\end{array}$ & $\begin{array}{c}\text { Unit Sel, a0 } \\
(\mathbf{\AA})\end{array}$ \\
\cline { 2 - 5 } & 1455 & 36,513 & 34,4 & 42,2 \\
\hline 18 & 4226 & 39,692 & 100 & 45,8 \\
\hline 24 & 2596 & 39,913 & 61,4 & 46,1 \\
\hline 48 & 1871 & 41,700 & 44,3 & 47,6 \\
\hline 88 & & \multicolumn{4}{|c|}{} \\
\hline
\end{tabular}

keterangan: $\mathrm{a}_{0}=$ unit sel pori dihitung dengan persamaan $\frac{2 d}{\sqrt{3}}$

MCM-41 yang disintesis dengan waktu hidrotermal 24 jam merupakan material dengan intensitas relatif $100 \%$ menandakan puncak pada $\mathrm{d}_{100}$ yang merupakan indikasi keteraturan pori-pori heksagonalnya merupakan yang tertinggi dengan yang lainnya.

\section{a. Uji Kapasitas Adsorpsi MCM-41}

Model adsorpsi isoterm perlu dilakukan untuk menentukan proses adsorben melakukan adsorpsi terhadap adsorbat. Penentuan model adsorpsi ini sangat penting karena untuk menggambarkan proses terjadinya adsorpsi. Model adsorpsi isoterm yang banyak digunakan ialah model Langmuir dan model Freundlich. Model adsorpsi isoterm Langmuir merupakan suatu proses adsorpsi satu lapis (monolayer) artinya jumlah situs aktif yang ada dalam adsorben mengadsorpsi adsorbat dengan jumlah yang sama, sedangkan model adsorpsi isoterm Freundlich menggambarkan suatu proses adsorpsi multilayer sehingga lebih berinteraksi secara fisisorpsi. MCM-41 yang disintesis dengan waktu hidrotermal 24 jam memiliki kemampuan adsorpsi terhadap metilen biru seperti gambar 2 .

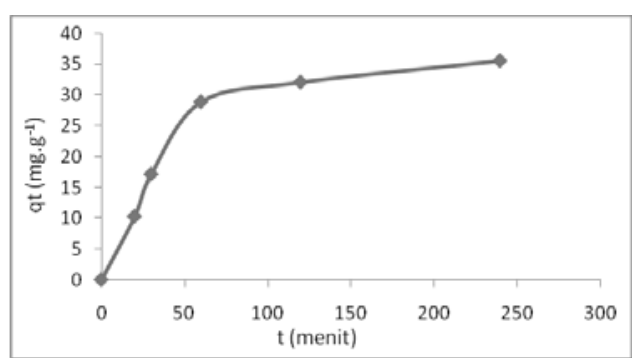

Gambar 2. Grafik Kapasitas adsorpsi MCM-41 terhadap Metilen Biru

Kapasitas adsorpsi MCM-41 dapat diperoleh dengan terlebih dulu menentukan jenis dari proses adsorpsinya mengikuti model Freudlich atau model Langmuir. Hasil penelitian ini mengindikasikan bahwa proses adsorpsi metilen biru terjadi pada MCM-41 secara monolayer pada permukaan MCM-41. Hal ini terlihat 
Tabel II. Konstanta adsorpsi isoterm Langmuir dan Freundlich untuk metilen biru

\begin{tabular}{lccccccc}
\hline & \multicolumn{3}{c}{ Langmuir } & \multicolumn{3}{c}{ Freundlich } \\
\cline { 2 - 7 } Material & $\begin{array}{c}\mathbf{q}_{\mathbf{m a x}} \\
(\mathbf{m g} / \mathbf{g})\end{array}$ & $\begin{array}{c}\mathbf{K}_{\mathbf{L}} \\
(\mathbf{L} / \mathbf{m g})\end{array}$ & $\mathbf{R}^{\mathbf{2}}$ & $\mathbf{1 / n}$ & $\begin{array}{c}\mathbf{K}_{\mathbf{F}} \\
(\mathbf{m g} / \mathbf{g})\end{array}$ & $\mathbf{R}^{\mathbf{2}}$ \\
\hline MCM-41 & 37,037 & 1,077 & 0,996 & 0,237 & 17,274 & 0,936 \\
\hline
\end{tabular}

dengan harga $\mathrm{R}^{2}$ yang dihasilkan oleh persamaan isoterm Langmuir lebih mendekati satu yang mengindikasikan bahwa hubungannya cenderung linier (Tabel II).

Tabel II. Memperlihatkan bahwa kemampuan adsorpsi maksimal MCM-41 terhadap metilen biru sebesar $37,037 \mathrm{mg} / \mathrm{g}$. Nilai ini menunjukkan kapasitas adsorpsi MCM-41 terhadap metilen biru.

\section{KESIMPULAN DAN SARAN}

\section{Kesimpulan}

Berdasarkan penelitian ini dapat disimpulkan bahwa MCM-41 yang disintesis dengan waktu hidrotermal 24 jam memiliki intensitas yang paling tinggi dimana hal ini juga menunjukkan bahwa MCM-41 tersebut memiliki kristalinitas yang lebih baik dan kapasitas adsorpsi MCM-41 terhadap metilen biru sebesar $37,037 \mathrm{mg} / \mathrm{g}$.

\section{Saran}

Penggunaan MCM-41 sebagai delivery system pada obat maka perlu dilakukan kajian proses adsorpsi pada obyek obat. Selain itu juga perlu kajian dissolusi/pelepasan obat pada material
MCM-41 dan bahkan uji in vitro atau bahkan in vivo.

\section{DAFTAR PUSTAKA}

Corma, Kan ,Navarro, Pariente, Rey, 1997, Synthesis of MCM-41 with Different Pore Diameters without Addition of Auxiliary Organics, Chem. Mater., 9, 2123-2126.

Kim, Kwak, Jun, Ryoo, 1995, Ion Exchange and Thermal Stability of MCM-41, J. Phys. Chem., 99 (45), 16742-16747.

Mody, Kannan, Bajaj,, Manu, Jasra, 2008, A simple room temperature synthesis of MCM-41 with enhanced thermal and hydrothermal stability, J. Porous Mater., 15:571-579.

Mokaya, 2001, Hydrothermallyinduced Morphological Transformation of Mesoporous MCM-41 Silica, Micropor. Mesopor. Mater, 44-45, 119-127.

Patil, Chirmade, Trivedi,Lamprou, Urquhart,Douroumis, 2011, Encapsulation of Water Insoluble Drugs in Mesoporous Silica Nanoparticles using Supercritical Carbon Dioxide, J. Nanomedic Nanotechnol, 2:3. 
Regi, 2012, Mesoporous Silica Nanoparticles: Their Projection in Nanomedicine, ISRN Materials Science.

Ryoo and Jun, 1997, Improvement of Hydrothermal stability of MCM-41 using salt effects during the crystallization process, $J$. Phys. Chem. B, 101, 317-320.

Ryoo and Kim, 1995, Structural Order in MCM-41 Controlled by Shifting
Silicate Polymerization Equilibrium, J. Chem. Soc., Chem. Commun., 711-712.

Xu, Luan, He, Zhou, Kevan, 1998, A Reliable Synthesis of Cubic Mesoporous MCM 48 Molecular Sieve, Chem. Mater., 10, 3690-3698. 